\title{
ASO Author Reflections: Advanced Imaging Allows Better Detection of Peritoneal Metastases
}

\author{
Nina Roelie Sluiter, MD and Jurriaan Benjamin Tuynman, MD, PhD \\ Department of Surgery, Cancer Center Amsterdam, Amsterdam UMC, Vrije Universiteit Amsterdam, Amsterdam, The \\ Netherlands
}

\section{PAST}

Peritoneal metastases (PM) are diagnosed in up to $30 \%$ of patients with colorectal cancer, especially in patients with $\mathrm{T} 4$ disease. ${ }^{1}$ Cytoreduction and hyperthermic intraperitoneal chemotherapy (HIPEC) improve the survival of patients with colorectal PM, resulting in an overall survival of 56 months in selected patients with limited peritoneal disease. ${ }^{2}$ Unfortunately, PM are often missed during elective primary tumor resection. Second, during follow-up after initial curative treatment, PM are mostly diagnosed in an advanced stage. Current diagnostic imaging modalities such as positron emission tomography/computed tomography (PET/CT) have a detection limit of $5 \mathrm{~mm}$ and the multiple small peritoneal lesions are frequently missed. ${ }^{3}$ The presence of advanced intra-abdominal disease such as omental cake can be easily visualized, but curative options in this stage are limited. Since cytoreduction and HIPEC results in good survival in patients with limited peritoneal disease, accompanied by a low morbidity due to the limited amount of resections, extensive effort should be made to improve early diagnosis of PM.

ASO Author Reflections is a brief invited commentary on the article, "Narrow-Band Imaging Improves Detection of Colorectal Peritoneal Metastases: A Clinical Study Comparing Advanced Imaging Techniques, ” Ann Surg Oncol. https://doi.org/10.1245/s10434-0187005-5.

(C) The Author(s) 2018

First Received: 14 November 2018; Published Online: 26 November 2018

N. R. Sluiter, MD

e-mail: n.sluiter@vumc.nl

\section{PRESENT}

Advanced imaging could improve the detection of PM during elective colorectal cancer resection and diagnostic laparoscopy. Narrow-band imaging (NBI), near-infrared indocyanine green fluorescence imaging (NIR-ICG), and spray-dye chromoendoscopy (SDCE) were prospectively compared with white-light imaging for the detection of PM in 28 patients. ${ }^{4} \mathrm{NBI}$ substantially increased sensitivity from $80.0 \%$ with white light to $96.0 \%$ ( $p=0.008)$, without loss of specificity ( $73.1 \%$ vs. $74.8 \%, p=0.804$ ). NIR-ICG and SDCE were not considered of value: NIR-ICG did not result in fluorescent PM and SDCE did not visualize the whole peritoneum.

NBI is not only a promising and safe method but is also practical, time efficient, and does not require extra costs. Its main implication could be early detection of PM during evaluation of the peritoneum at the time of primary tumor resection. This allows early referral to specialized HIPEC centers, which is key for oncologic outcome. Second, NBI could help determine feasibility of a complete cytoreduction prior to HIPEC. Third, improved visualization of PM may optimize cytoreduction.

\section{FUTURE}

NBI is a practical technique that is available on most laparoscopic systems, facilitating quick translation into clinical practice. Fluorescence with antibody-coupled ICG is a promising method but is currently not widely available and requires further research prior to clinical implementation. Issues to be addressed include identification of optimal antibody targets (vascular endothelial growth factor or carcinoembryonic antigen) and cost-effectiveness. Furthermore, investigation of the value of advanced imaging in terms of oncologic outcomes is pivotal, warranting prospective randomization between techniques. 
Currently, a trial evaluating second-look diagnostic laparoscopy after $\mathrm{T} 4$ colorectal cancer resection aims for detection of PM at a clinically occult stage, which is expected to translate into survival benefit (ClinicalTrials.gov: NCT03413254). To further improve survival of patients with colorectal PM, early diagnosis by advanced (epi-)genetic analyses in peripheral blood as liquid biopsies has been studied. ${ }^{5}$ Together with advanced intraoperative tumor detection, this could allow for cytoreduction and HIPEC in an early and curable stage of peritoneal disease, and, consequently, improve oncologic outcomes.

DISCLOSURES Nina Roelie Sluiter and Jurriaan Benjamin Tuynman have no conflicts of interest to disclose.

OPEN ACCESS This article is distributed under the terms of the Creative Commons Attribution 4.0 International License (http://crea tivecommons.org/licenses/by/4.0/), which permits unrestricted use, distribution, and reproduction in any medium, provided you give appropriate credit to the original author(s) and the source, provide a link to the Creative Commons license, and indicate if changes were made.

\section{REFERENCES}

1. Koppe MJ, Boerman OC, Oyen WJ, Bleichrodt RP. Peritoneal carcinomatosis of colorectal origin: incidence and current treatment strategies. Ann Surg. 2006;243(2):212-22.

2. Sluiter NR, Rovers KP, Salhi Y, et al. Metachronous peritoneal metastases after adjuvant chemotherapy are associated with poor outcome after cytoreduction and HIPEC. Ann Surg Oncol. 2018;25(8):2347-56.

3. Koh JL, Yan TD, Glenn D, Morris DL. Evaluation of preoperative computed tomography in estimating peritoneal cancer index in colorectal peritoneal carcinomatosis. Ann Surg Oncol. 2009;16(2):327-33.

4. Sluiter NR, Vlek SL, Wijsmuller AR, Brandsma HT, De Vet $\mathrm{HCW}$, Van Grieken NCT, et al. Narrow-band imaging improves detection of colorectal peritoneal metastases: a clinical study comparing advanced imaging techniques. Ann Surg Oncol. https://doi.org/10.1245/s10434-018-7005-5

5. Wan JC, Massie C, Garcia-Corbacho J, et al. Liquid biopsies come of age: towards implementation of circulating tumour DNA. Nat Rev Cancer. 2017;17(4):223-238. 